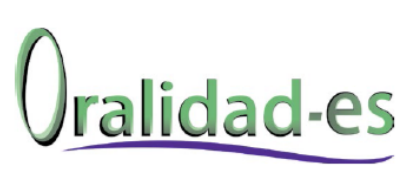

REVISTA DE LA RED IBEROAMERICANA DE ESTUDIOS

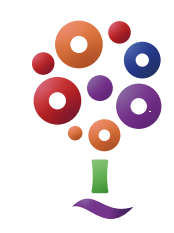

\title{
Entrevista realizada al profesor Gastón Salamanca
}

\author{
Interview with Professor Gastón Salamanca
}

\author{
Lizbeth Alejandra Gómez-Aliste \\ Liz.gomez.a@gmail.com \\ Universidad del Bío-Bío (UBB), Chile
}

Gómez-Aliste, L. A. (2019). Entrevista realizada al profesor Gastón Salamanca. Oralidad-es, 5, 1-9. https://revistaoralidad-es.com/index.php/ro-es/article/view/116/85

Fecha de recepción: 22 de mayo de 2019 - Fecha de aprobación: 15 de septiembre de 2019

(c) (1) 


\section{Resumen}

El profesor Gastón Salamanca Gutiérrez es doctor en lingüística de la Universidad de Concepción en Chile. Ha publicado decenas de artículos relacionados con su área en estudios realizados en el país, con investigaciones novedosas y necesarias sobre el español hablado en Chile. No obstante, la mayoría de sus investigaciones se han centrado en el estudio de las lenguas vernáculas de Chile, centrándose en algunos idiomas como el mapundungún y el chedungún, entre otros. Es por ello, que lo hemos invitado para conversar sobre sus trabajos y sus pensamientos a cerca de estos y de la importancia que tienen en el área

\section{Palabras clave}

Gastón salamanca; lingüística; lenguas vernáculas;

formación docente; enseñanza

\section{Abstract}

Gastón Salamanca Gutiérrez holds a doctorate in Linguistics from the Universidad de Concepción, Chile and has extensive research work on Chilean Spanish,and native languages such as Mapundungun and Chedungun. The interview addresses professor Salamanca Gutiérrrez 'research findings on the impact of the raising your voice and arguing orally while teaching college-level students, especially, within the initial teaching training programs nationwide.

Keywords

Professor Gastón Salamanca; linguistics; western languages; initial teaching training 
Imagen 1

Profesor Gastón Salamanca

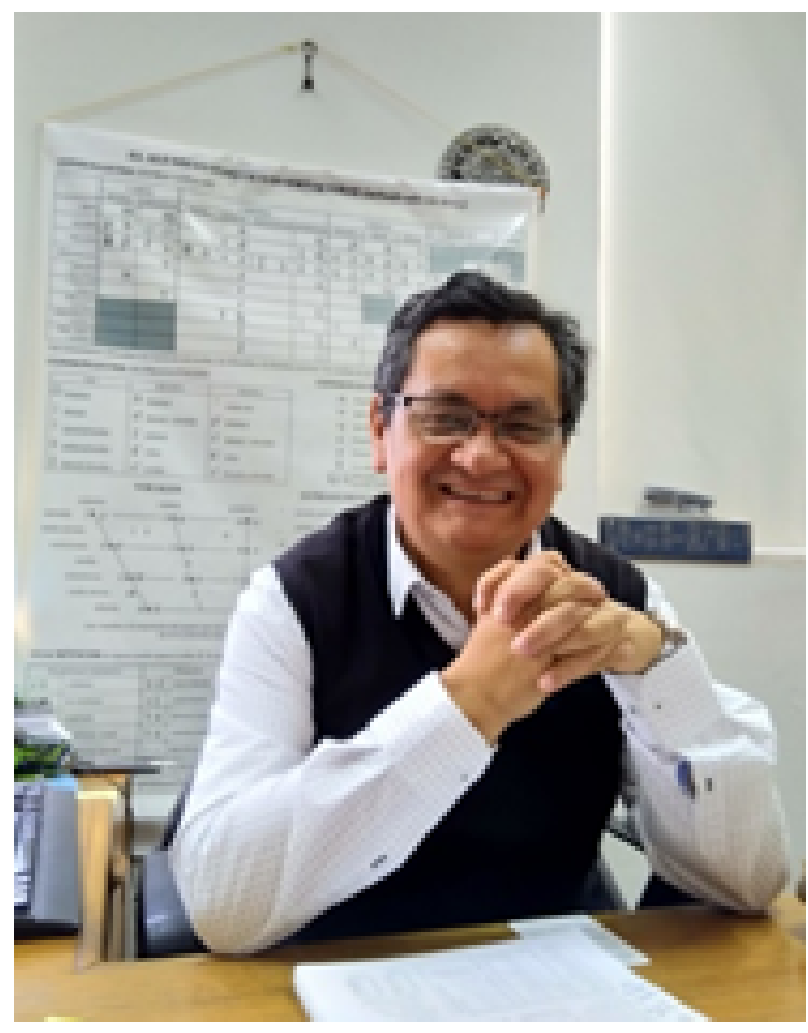

Fuente: Elaboración propia

Entrevistadora: Buenos días profesor Gastón, muchas gracias por acceder a darnos algo de su tiempo para contestar algunas preguntas.

Profesor Gastón: No, todo lo contrario, gracias a ustedes por tenerme en cuenta y querer conversar conmigo sobre mi profesión.

Entrevistadora: ¿De dónde surge el interés por estudiar las lenguas vernáculas chilenas?

Profesor Gastón: Creo que fue decisiva la influencia del Dr. Adalberto Salas, quien dedicó buena parte de su vida al estudio de estas lenguas $\mathrm{y}$ con quien tuve el privilegio de formarme en lingüística. A partir de sus clases, pude fascinar- me con aspectos de la estructura y cosmovisión plasmadas en estas lenguas y decidir que este iba a ser uno de los focos prominentes de mi quehacer como investigador.

Entrevistadora: ¿Cree que hacen falta más estudios sobre estas lenguas?

Profesor Gastón: Mi respuesta es categóricamente afirmativa. Y esto resulta más urgente si se considera que las proyecciones respecto del mantenimiento de las lenguas originarias en el mundo en general y en Chile en particular no son para nada alentadores. Un botón de muestra es que en el extremo sur de nuestro país vive la Sra. Cristina Calderón, quien puede considerarse la última hablante de la lengua yagán. Otra lengua fueguina, el kawésqar (alacalufe), también está seriamente amenazada con desaparecer. Sin embargo, un dato auspicioso: dos jóvenes colegas míos están viajando en estos momentos a Puerto Edén para poder hacer registro de ella.

Por otro lado, podríamos pensar que el mapudungun, por la cantidad de personas que se autoidentifican como pertenecientes a la etnia mapuche, podría estar en una situación ostensiblemente mejor. Sin embargo, los estudios desde el 2000 hasta hoy muestran que el intenso proceso de desplazamiento que ha sufrido históricamente la lengua, no se ha revertido, ni siquiera estabilizado.

Entrevistadora: Usted dice que sí son necesarios más estudios sobre este tema ¿A qué áreas de estudio debiese dársele más énfasis en este aspecto?

Profesor Gastón: Desde mi lugar como lingüista, puedo señalar que si bien es cierto hay algunos aportes históricos sustantivos en ámbi- 
tos como la fonología o la morfología de algunas de ellas, no se podría decir lo mismo en niveles como el sintáctico, semántico o discursivo.

Ahora, aportes más, aportes menos, lo claro es que en cada uno de los niveles de análisis de nuestra disciplina se requiere seguir contribuyendo de manera sustantiva, pues, por ejemplo, y como hemos señalado, aunque hay desarrollos históricos muy importantes en niveles como el fonológico o el morfológico en una lengua como el mapudungun, el refinamiento de los marcos de referencia en la actualidad, puede ayudar a iluminar zonas del conocimiento que no habían sido explorados y/o a despejar aspectos que han sido motivo de controversia histórica entre los estudiosos de estas lenguas. Sólo porque están en mi órbita más próxima, con todo el sesgo y la injusticia que ello implica, quiero reconocer la contribución que colegas muy jóvenes, a quienes tuve el privilegio de dictarles al menos un curso en su formación académica, están haciendo al conocimiento de las lenguas minoritarias y minorizadas presentes en Chile. En efecto, vaya todo mi reconocimiento al trabajo de mis colegas Daniela Mena y Mauricio Figueroa (en el ámbito fonético-fonológico); Rodrigo Becerra, Alonso Soto, Diego Lizarralde (en el ámbito de la gramática y la semántica); y Marisol Henríquez y Aldo Olate (en el ámbito de la lingüística de contacto).

Ahora, sin duda, tanto o más importante que el trabajo que se debe realizar a nivel teórico, es el que se debe desarrollar a nivel aplicado; especialmente, en lo que respecta al rescate y la (re) vitalización de estas lenguas. Creo, en efecto, que la contribución desde la lingüística en Chile al desarrollo de políticas que contribuyan de manera sustantiva a la enseñanza-aprendizaje de las lenguas que nos ocupan es algo pendiente. En ello, sin duda, países como México o Perú, por nombrar solo dos, nos llevan mucha ventaja.
Entrevistadora: ¿Cree que deban enseñarse las lenguas vernáculas en las instituciones educacionales?

Profesor Gastón: También aquí, como era de esperar, mi respuesta es un categórico "sí". Daré tres argumentos que no por el hecho de ser frecuentemente señalados dejan de ser ciertos. En primer lugar, porque conocer otra lengua implica conocer otra forma en que el ser humano, como especie, ha plasmado una forma particular de apropiarse conceptualmente del mundo. Hay un valor ecológico, sin duda, en conocer cómo en el ámbito de los sonidos, de la gramática, de los significados, del uso de la lengua, una cultura puede presentar simetrías y desfases interesantísimos respecto de otra. También hay un valor ético en la enseñanza de las lenguas vernáculas, en el sentido de que estas han sido lenguas que, junto con sus hablantes, han sido históricamente discriminados o, lisa y llanamente, hechos desaparecer; de modo que el conocerlas y situarlas en el mismo nivel de aquellas a las cuales se les ha asignado prestigio y que se enseñan en las instituciones educacionales conlleva otro valor, sin duda. Por último, hay razones cognitivas también, pues hay evidencias que apoyan la hipótesis de que el aprendizaje de una segunda lengua ayuda a la aprehensión y afianzamiento de otras competencias.

Pero no quisiera dejar pasar la oportunidad para señalar un aspecto que me parece muy importante a propósito de esta pregunta. Pienso que un aspecto que puede contribuir a la revitalización de nuestras lenguas originarias es, precisamente, su enseñanza, pues el conocerlas debería implicar, de entrada, desmontar muchos prejuicios que existen respecto de ellas, como que no son verdaderas lenguas, sino meros dialectos, que no tienen gramática, que tienen un léxico pobre, etc. Es decir, se puede establecer a poco andar del proceso de enseñanza-aprendizaje, lo que la lingüística ha proclamado en todos los 
tonos, esto es, que nuestras lenguas vernáculas tienen sobradamente el estatus de tales y no constituyen meras secuencias de sonidos ininteligibles que carecen de toda estructuración. Afianzado esto, es la "apuesta”, un componente central de discriminación debería desmoronarse o al menos atenuarse, con todo lo que ello implica en el proceso de afianzamiento de una genuina interacción intercultural. Pido perdón por lo autorreferente, pero traeré a colación aquí las palabras que vertí en un trabajo donde me pronuncio respecto del rol que como sociedad mayoritaria nos ha tocado históricamente en el proceso de pérdida y desplazamiento de nuestras lenguas originarias y, especialmente, del que podríamos jugar, en el mejor de los casos, en el de su posible reversión. Lo leeré: "Consideramos que un camino posible para sobrevivir [nuestros grupos vernáculos] a este paso avasallador de la globalización cultural en el Chile de hoy está en revalorizar sus aspectos culturales y lingüísticos desde la sociedad mayoritaria. La reivindicación territorial de la propia etnia es fundamental, sin duda, pero la experiencia me indica que un mapuche puede tener resuelto el problema territorial, pero si observa que en el día a día su lengua, vestimenta, ritos, etc. carecen de prestigio, particularmente en la urbe, se siente absolutamente desmotivado para proyectárselos a sus hijos. Sin esta actitud de la sociedad mayoritaria, que por cierto debe correr en paralelo con el proceso reetnificación que nace y se afianza en la propia etnia, nos parece que el proceso homogeneizador avanzará inexorable para nuestros grupos vernáculos”.

Dicho en breve, como sociedad chilena históricamente hemos sido muy activos en el proceso de desplazamiento y pérdida de nuestras lenguas originarias, pero extremadamente pasivos en contribuir en el proceso de su (re)vitalización. $\mathrm{Y}$ en esto hay responsabilidad tanto de nuestros estamentos más conspicuos, como de la Señora Juanita. Léanse estas consideraciones, por cierto, como un emplazamiento transversal a ser pro- tagonistas en los procesos de (re)vitalización de nuestras lenguas originarias, y con ello la reivindicación de sus hablantes, y no de su desplazamiento y pérdida.

Entrevistadora: Entonces ¿Cómo cree usted que debiese llevarse este proceso de formación de profesores para la enseñanza de las lenguas vernáculas?

Profesor Gastón: Aparte de todas las consideraciones administrativas que se deben tener presente al momento de considerar este proceso, creo que un aspecto central a tener presente es el perfil de dichos profesores (tanto de los formadores como de los que serán formados). Y en ese sentido, desde mi punto de vista, algunos rasgos de este perfil debieran ser, primero, una sólida formación en lingüística, tanto teórica como aplicada. Esto porque si se quiere tener profesores que tengan la convicción de que, por ejemplo, las lenguas vernáculas tienen todas las propiedades que caracterizan las lenguas humanas, que no son meros dialectos, que hay simetrías y desfases entre las lenguas vernáculas estudiadas y las lenguas mayoritarias, etc., necesitan conocer lo que la lingüística ha dicho al respecto, usando un metalenguaje apropiado. Segundo, una sólida formación pedagógica, especialmente en didáctica. Aunque creo que muchas de las competencias que tiene un docente para cautivar la atención de su auditorio no son del todo enseñables ni aprendibles en un aula, me parece que una característica es que dicho docente debe estar abierto a que algunas herramientas no tradicionales puedan apoyar su quehacer. En este sentido, debo valorar iniciativas como las del colectivo Kimeltuwe, que a través de imágenes muy logradas y amigables logran plasmar y socializar muchos aspectos léxicos, gramaticales y de interacción en la lengua mapuche. También destaco el trabajo de la agrupación cultural Voces de la Tierra, que a través de plataformas 
digitales también provee de materiales para la enseñanza-aprendizaje de algunas de nuestras lenguas vernáculas. En un formato un tanto más tradicional, pero de gran solidez como método de enseñanza-aprendizaje del mapudungun, destaco también la reciente publicación de Folil Mapudungun, de, entre otros autores, Wenceslao Norín y Rodrigo Becerra.

Por último, creo que es necesario tener convicción del valor de la interculturalidad. Para mí, el escenario óptimo para desplegar un proceso de formación de profesores para la enseñanza de las lenguas vernáculas es aquel en el que hablantes nativos altamente competentes en el despliegue de su lengua y cultura se hacen cargo de dicho proceso. Aquí me detengo un minuto para señalar lo que me parece un escenario muy enriquecedor, el cual es que algunos hablantes nativos de nuestras lenguas originarias han obtenido, o cursan los programas que los llevarán a obtener, los grados más avanzados de formación académica (doctorados). Me parece que es un escenario enriquecedor, porque es una buena muestra de lo que entiendo como una relación intercultural sólida, pues, lejos de renunciar a sus saberes ancestrales, lo que incluye su lengua, por supuesto, estos hablantes se familiarizan con otras maneras de acceder al conocimiento, las cuales pueden complementar y enriquecer aquellas que les han sido transmitidas de manera tradicional por su cultura; y como contrapartida, al ser por lo general estos estudiante muy buenos difusores de su cultura, posicionan y despliegan su lengua en un ambiente generalmente poco permeable a la alteridad como es el académico. Para poner nombres y apellidos, y otra vez con la injusticia que esto significa, destaco la figura de don Héctor Painequeo y de don Gabriel Llanquinao, a quienes tuve el gusto de conocer, precisamente, en este contexto académico.

Pero claro, hoy por hoy esta ecuación es la excepción, de modo que el escenario de formación de profesores de lenguas vernáculas ha requerido, y seguramente seguirá requiriendo, del concurso de personas que no pertenecen a la etnia, y en este contexto, creo que no es demasiado pedir el hecho de que alguien que participe en él tenga, al menos, una experiencia transcultural, lo que quiere decir que su conocimiento acerca de la lengua y cultura vernácula que enseñe no se limite a una buena bibliografía sobre el particular. Relevo este punto, porque me parece que uno de los grandes desafíos que debe tener la formación de futuros docentes de lenguas originarias es plasmar en sus egresados la convicción de que es justo y necesario que la sociedad que no adscribe a ningún grupo originario conozca, desprejuiciadamente, acerca de nuestras lenguas vernáculas y en lo posible hable una de ellas, y sea capaz de transmitir esta convicción; al mismo tiempo, quienes formen a estos profesores deben ser capaces de transmitir a quienes egresen la convicción de que es valioso que aquellos miembros de la etnia que dejaron de hablar su lengua vernácula o nunca lo hicieron se integren en instancias que permitan recuperarla o aprenderla, y que sean capaces también de transmitir esta convicción a quienes están en este estatus; por último, y muy importante, quienes formen futuros profesores deberían plasmar en los futuros egresados la convicción de que es valioso que aquellos miembros que pertenecen a nuestros grupos originarios y hablan la lengua, la transmitan a sus hijos (lo que, por lo demás, es la modalidad más natural de adquisición y proyección de una lengua). Pero claro, para formar futuros profesores que hagan suyas estas convicciones y las transmitan es necesario que quienes los formen las hayan hecho propias, desde lo racional, lo emocional y lo factual. Dicho a modo de pregunta, y en palabras coloquiales, ¿con qué ropa un formador de futuros profesores de lenguas vernáculas podrá plasmar en sus alumnos la convicción de que hablar dichas lenguas es algo valioso desde un punto de vista ecológico, ético y cognitivo, si ni siquiera él cree en ello?... 
Todo esto, por supuesto, se concibe como un complemento a iniciativas que se gesten desde las propias comunidades y, sobretodo, como complemento a la forma tradicional de transmisión de una lengua, que, como hemos señalado, en su forma minimalista, sólo requiere que esta se hable de manera natural para que el niño la adquiera, pero que ha sido, precisamente, lo que se ha descontinuado de manera dramática.

Entrevistadora: Sabemos que no solo ha estudiado las lenguas vernáculas ¿Qué otras áreas de la lingüística ha investigado?

Profesor Gastón: Junto con el estudio de aspectos de la lengua de los gitanos (romané) y de los mapuche (mapudungun), he realizado algunos trabajos en autoría y en coautoría sobre el español de Chile. Por ejemplo, en el aspecto fónico, me ha interesado el prestigio y la estigmatización en variantes anteriorizadas y posteriorizadas de las vocales del español de Chile, también participé en la propuesta de un inventario de fonos y su transcripción para el español de Chile; en el plano léxico, me ha interesado la presencia de argentinismos en el español de Chile y el uso coloquial de algunos términos de parentesco (como en las expresiones "¿qué va a llevar mamita?", "pase no más, papi"; "Tio, deje una moneíta", etc.). También tengo un trabajo en coautoría sobre los fonos presentes en la glosolalia (hablar en lenguas) de tres hispanohablantes; y varios sobre los estereotipos sociales asociados a nombres propios que se usan en Chile, porque en Chile, como sabemos, no da lo mismo llamarse Jason o Bryan, que llamarse Maximiliano o Raimundo. Ah y junto a mi colega y amigo Edgardo Cifuentes nos hemos interesado también en el tema de la neutralización de contraste fonológico y la elisión consonántica como mecanismos de innovación léxica. En este trabajo, nos interesa poner en foco oposiciones como "buena" (mujer de valor moral positivo) versus "güena" (mujer físicamente atractiva) y "cueva" (cavidad natural o artificial) versus "cuea" (fortuna, suerte), respectivamente.

Entrevistadora: ¿Cuáles consideraría que son los aportes más relevantes que se han realizado en Chile en materia de lingüística y oralidad?

Profesor Gastón: Creo que lo que se ha hecho desde la lingüística en relación con el estudio de nuestras lenguas originarias constituye un aporte sustantivo de la lingüística a los estudios sobre la oralidad. En esto hago un reconocimiento especial a la tarea que llevó a cabo en su momento la Universidad de Playa Ancha, a través de su CELTO (Centro de Estudios de Lenguas de Tradición Oral). Especialmente, vaya mi reconocimiento al Dr. Daniel Lagos, quien tuvo un rol determinante en el diseño e implementación de este referente en el estudio de nuestras lenguas originarias y que en estos días se encuentra muy delicado de salud.

En relación con el estudio del español de Chile, hay aportes recientes importantes, como la propuesta de inventario fonético de Sadowsky y Salamanca, especialmente por su carácter inclusivo (no sólo se incluyen los fonos que caracterizan el habla culta, sino que también aquellos que se presentan en los niveles socioculturales menos privilegiados); también, por supuesto, son contribuciones importantes el Diccionario de Uso del Español de Chile, muchas publicaciones sobre el estudio de la metáfora lingüística y trabajos recientes sobre neologismos en nuestra variante del español. Pero a mucha distancia, en todo caso, de lo que es, por ejemplo, la tradición y producción de la Academia del Lunfardo en Argentina. 
Entrevistadora: ¿Cuáles consideraría que son los temas que más faltan investigar en Chile en materia de lingüística y oralidad?

Profesor Gastón: Son muchos, sin duda. Evidentemente, seguir profundizando el estudio de nuestras lenguas originarias es un desafío plenamente vigente para nuestra disciplina.

En relación con el español de Chile, en el nivel fonético-fonológico segmental sería importante chequear las hipótesis que se contienen en el trabajo de Sadowsky y Salamanca, pues, tal como hemos plasmado en el mismo estudio, el objetivo final de este artículo es motivar la realización de un caudal de trabajos que investiguen tanto los supuestos teórico-metodológicos contenidos en la propuesta, como la selección y caracterización de los fonos del inventario provisorio. También sería importante realizar un mayor caudal de estudios en el plano suprasegmental, pues, en general este plano tiene un nivel de desarrollo aún incipiente, por lo menos si se compara con el plano segmental.

Con respecto al estudio del léxico, creo que es importante comenzar a evaluar la incidencia que está teniendo la migración en nuestra variante del español, a la vez que seguir profundizando en la eventual influencia del componente indoamericano en ella. En este sentido, es interesante el resurgir de la tesis indigenista de Lenz con las propuestas de Sadowsky. También me parece importante seguir estudiando la influencia del lunfardo argentino en nuestra variante del español, propuesta que tiene precedentes en los trabajos de San Martín y de quien les habla.

Una temática que en términos personales me parece muy interesante de indagar en el español no estándar de Chile es la cuantificación. Con respecto a ella, se pueden considerar varias expresiones como: "caleta de" (como en "el viejito tenía caleta de años" o "me alegré caleta”), "una cachá de" (como en "había una cachá de autos en la calle"), "una pila de x cosas", "un kilo” (como en "sufrí un kilo por esa situación”), "harto" (como en "hace harto tiempo que no entro al facebook"), "terrible de" (como en "estaba terrible'e preocupao"), "una tirá de" (como en "tuve que presentar una tirá de papeles"), "una manga de" (como en "todos son una manga de flaites"), "una chorrera de (como en "me salió con una chorrera de excusas"), "ene (cantidad de)" o "lo respeto ene"), "uno que otro" (como en "estuve mirando uno que otro auto para ver si me lo compro"), "mah o menoh", "la pe" (como en "le entendí la pe"), "una cagá" (como en "están pagando una cagá"), "la nada misma” (como en "tuve que esperar la nada misma"), "un pelo de la cola” (lo que tengo que pagar es un pelo de la cola"), "una raja" (como en "me importa una raja que le peguen"), "del verbo + adj." (como en "el local era del verbo malo"), etc. Sin duda que un análisis intra y sociolingüístico sobre este tópico revelaría muchos aspectos estructurales y culturales interesantes respecto de fenómenos presentes en nuestra variante del español. Sólo por citar uno de ellos, me parece muy interesante considerar los cuantificadores "(una) cagá” y "(una) raja” (me disculpo si suena mal, pero es una realidad de nuestra habla cotidiana), los cuales portan un significado claro de "(muy) poco". Sin embargo, este significado de exiguo, con claros tintes negativos, no es siempre el que se acuña en los ámbitos donde ocurren instanciaciones de los lexemas correspondientes, lo que se puede apreciar en expresiones como: "En todas partes nos cagan" versus "buenísima la película, la cagó" o "les volamos la raja" contra "es un car'e raja” o "Es la raja tal cosa".

En el fondo, si se da cuenta, en la expresividad concerniente a la cuantificación, "una cagá" y "una raja" siempre plasman un significado peyorativo y no de ponderación positiva; sin embargo, en otros contextos pueden manifestarse ambos significados, como se observa, por ejemplo, en el caso de "buenísima la película, la cagó", y "es un compadre a toda raja”. Así, entonces, el 
análisis de los datos se enriquece sobremanera con esta una entrada semasiológica y onomasiológica a los datos.

Creo, por último, que una cantera que puede ofrecer mucha información, tanto para indagaciones teóricas como descriptivas, es el habla carcelaria, pero que, por una multiplicidad de factores, entre ellos, un cierto elitismo de la academia, en lo que a las variantes del español estudiables se refiere, no lo han propiciado como foco de atención prominente.

Entrevistadora: ¿Cree en hay real interés en Chile por realizar más estudios en el ámbito de la lingüística y oralidad?

Profesor Gastón: Creo que en algunos sectores sí hay tal interés, pero constituyen, sin duda, una minoría. Esto, entre otras cosas, porque, aunque está en el credo del lingüista: "prestaré atención tanto a las lenguas prestigiosas como a las de minorías" y "prestaré igual atención a los registros culto-formales, como a aquellos propios de la coloquialidad y la oralidad", es claro que la mayor ocupación en tiempo y recursos se lo lleva el estudio de las lenguas mayoritarias y los registros culto-formales. Podríamos decir que los estudios sobre oralidad siguen siendo parientes pobres en la familia de los estudios lingüísticos, pero estos parientes pobres son trabajadores y disciplinados, de modo que no sería extraño que en plazo no muy lejano pasaran a ser parte de los nuevos ricos de esta disciplina (sonríe).

Entrevistadora: Muchas gracias profesor por su tiempo y su buena disposición. No queda duda de lo importante que es continuar realizando investigaciones en estas áreas.
Profesor Gastón: Así es, muchas gracias a ustedes por escucharme. 